\title{
The relevance of applying exercise training principles when designing therapeutic interventions for patients with inflammatory myopathies: a systematic review
}

\author{
Pierrette Baschung Pfister ${ }^{1,2,3}$ • Eling D. de Bruin ${ }^{3,4,5}$. \\ Bernadette C. Tobler-Ammann ${ }^{1,3} \cdot$ Britta Maurer $^{6} \cdot$ Ruud H. Knols ${ }^{1}$
}

Received: 30 March 2015 / Accepted: 23 July 2015 / Published online: 14 August 2015

(C) Springer-Verlag Berlin Heidelberg 2015

\begin{abstract}
Physical exercise seems to be a safe and effective intervention in patients with inflammatory myopathy (IM). However, the optimal training intervention is not clear. To achieve an optimum training effect, physical exercise training principles must be considered and to replicate research findings, FITT components (frequency, intensity, time, and type) of exercise training should be reported. This review aims to evaluate exercise interventions in studies with IM patients in relation to (1) the application of principles of exercise training, (2) the reporting of FITT components, (3) the adherence of participants to the intervention, and (4) to assess the methodological quality of the included studies. The literature was searched for exercise studies in IM patients. Data were extracted to evaluate the application of the training principles, the reporting of and the adherence to the exercise prescription. The Downs and Black checklist was used to assess methodological quality
\end{abstract}

Electronic supplementary material The online version of this article (doi:10.1007/s00296-015-3343-9) contains supplementary material, which is available to authorized users.

Pierrette Baschung Pfister

pierrette.baschung@usz.ch

Eling D. de Bruin

eling.debruin@hest.ethz.ch

Bernadette C. Tobler-Ammann

bernadette.tobler@usz.ch

Britta Maurer

Britta.maurer@usz.ch

Ruud H. Knols

ruud.knols@usz.ch

1 Physiotherapy and Occupational Therapy Research, Directorate of Research and Education, University Hospital Zurich, Gloriastrasse 25, 8091 Zurich, Switzerland of the included studies. From the 14 included studies, four focused on resistance, two on endurance, and eight on combined training. In terms of principles of exercise training, $93 \%$ reported specificity, $50 \%$ progression and overload, and $79 \%$ initial values. Reversibility and diminishing returns were never reported. Six articles reported all FITT components in the prescription of the training though no study described adherence to all of these components. Incomplete application of the exercise training principles and insufficient reporting of the exercise intervention prescribed and completed hamper the reproducibility of the intervention and the ability to determine the optimal dose of exercise.

Keywords Myositis $\cdot$ Inflammatory myopathy $\cdot$ Aerobic exercise $\cdot$ Resistance training $\cdot$ Training principles . Training components
2 Department of Health, Institute of Physiotherapy, Zurich University of Applied Sciences, Winterthur, Switzerland

3 Department of Epidemiology, CAPHRI School for Public Health and Primary Care, Maastricht University, PO Box 616, 6200 MD Maastricht, The Netherlands

4 Department of Health Sciences and Technology, Institute of Human Movement Sciences and Sport, ETH Zurich, Zurich, Switzerland

5 Centre for Evidence Based Physiotherapy, Maastricht University, PO Box 616, 6200 MD Maastricht, The Netherlands

6 Division of Rheumatology and Laboratory for Systemic Autoimmune Diseases, University Hospital of Zurich, Zurich, Switzerland 


$\begin{array}{ll}\text { Abbreviations } \\ \text { DM } & \text { Dermatomyositis } \\ \text { FITT } & \text { Frequency, intensity, time, and type of exercise } \\ \text { IBM } & \text { Inclusion body myositis } \\ \text { IM } & \text { Inflammatory myopathies } \\ \text { PE } & \text { Physical exercise } \\ \text { PM } & \text { Polymyositis } \\ \text { RCT } & \text { Randomised controlled trail } \\ \text { RPE } & \text { Rating of perceived exertion and pain }\end{array}$

\section{Introduction}

Dermatomyositis (DM), polymyositis (PM), and inclusion body myositis (IBM) belong to inflammatory myopathies (IMs), a group of autoimmune syndromes leading to chronic diseases of the musculature characterised by proximal muscle weakness. IM may also be present as a part of a multisystem disorder in other connective tissue diseases, most commonly scleroderma, systemic lupus erythematosus, mixed connective tissue diseases, and Sjögren Syndrome [1]. Several epidemiological studies report incidence rates varying widely between 0.1 and 7.89 cases per 100,000 annually [2-4]. Interestingly, recent publications show a higher incidence rate than previous studies, indicating increased awareness of this disease but also improved screening methods [5]. Although relatively rare, IMs pose a significant economic burden causing increased medical costs and resource usage as well as high patient burden $[6,7]$. The most prominent clinical features in all subcategories of IM are proximal and (often) symmetric muscle weakness and low muscle endurance, combined with progressive decline over a period of weeks or months. These features result in significant disabilities [8, 9]. Patients often report increasing difficulties in performing everyday tasks, such as self-care or household chores, combined with limited community mobility [1, 8]. Additionally, muscle weakness is a known risk factor for postural instability and falls $[10,11]$, and there is evidence that falling is common in patients with IBM [8]. The benefit of targeted physical exercise (PE) in patients with IM has been acknowledged and resulted in the inclusion of physical training which aims to improve performance without exacerbating disease progression in recognised treatment recommendations $[2$, $12,13]$. PE is a safe intervention and may not only improve strength and endurance but also seems to have anti-inflammatory, anti-fibrotic, and positive metabolic effects [2, 14-19]. An important prerequisite for PE to be effective is, however, the adherence to principles of exercise training [20-22]. A systematic review investigating the safety and efficacy of exercise in IM patients reported indecisive results [23]. Up to now, the published reviews describing exercise training in IM focused on safety and efficacy of physical exercise interventions, but did not critically evaluate the application of the principles of exercise training or the adherence to the prescribed exercise programme in a structured manner.

When reporting the results of a PE intervention, it is important to provide precise information regarding the core principles of PE training that were used and considered [20, 21]. Without a detailed and comprehensive description of the interventions, research findings cannot be used for replication in other studies or implementation in clinical daily routine [24]. The recognised principles of PE are specificity, overload, progression, initial values, reversibility, and diminishing returns (Table 1) [25]. Their implementation in the design of a PE intervention helps to ensure that an appropriate dose and type of exercise is utilised to achieve a desired outcome, be this improvements in cardiorespiratory endurance, muscular strength, or balance. Besides considering these core principles, it is also important to report the components of the exercise programme. Only if training is reported with this level of detail can appropriate study conclusions be drawn as well as intervention replication guaranteed. The components of a PE programme can be reported using the FITT components (frequency, intensity, time, and type of exercise) [26]. Furthermore, the adherence to the described FITT components should be captured and reported. Without reporting the adherence to the prescribed exercise programme, the dose that was delivered remains unclear. Therefore, the prescription of the components of the exercise programme as well as participants' adherence to that exercise prescription need to be reported in sufficient detail. Moreover, when principles of exercise training are applied to the development of exercise protocols, clinicians can assume that studies where the intervention of interest demonstrates a lack of significant effects reveal shortcomings in exercise efficacy rather than shortcomings in exercise prescription $[21,22]$. Some of the shortcomings of knowledge related to exercise implementation in IM patients might relate to the lack of consideration of exercise principles in the trials published so far.

Besides a specific and clearly planned and described intervention, other factors such as the design and methodological quality of a trial may influence study outcome. Well-designed randomised controlled trials provide the best evidence regarding the effectiveness of health-care interventions, whilst inadequate methodological approaches may overstate treatment effects and bias results [27]. Although non-randomised studies are more susceptible to confounding, their results in comparison with those of randomised trials may sometimes differ [28]. Furthermore, for some rare diseases, there may in any event be too few RCTs to answer the question of interest, thus necessitating that non-randomised trials also be included in review work. 


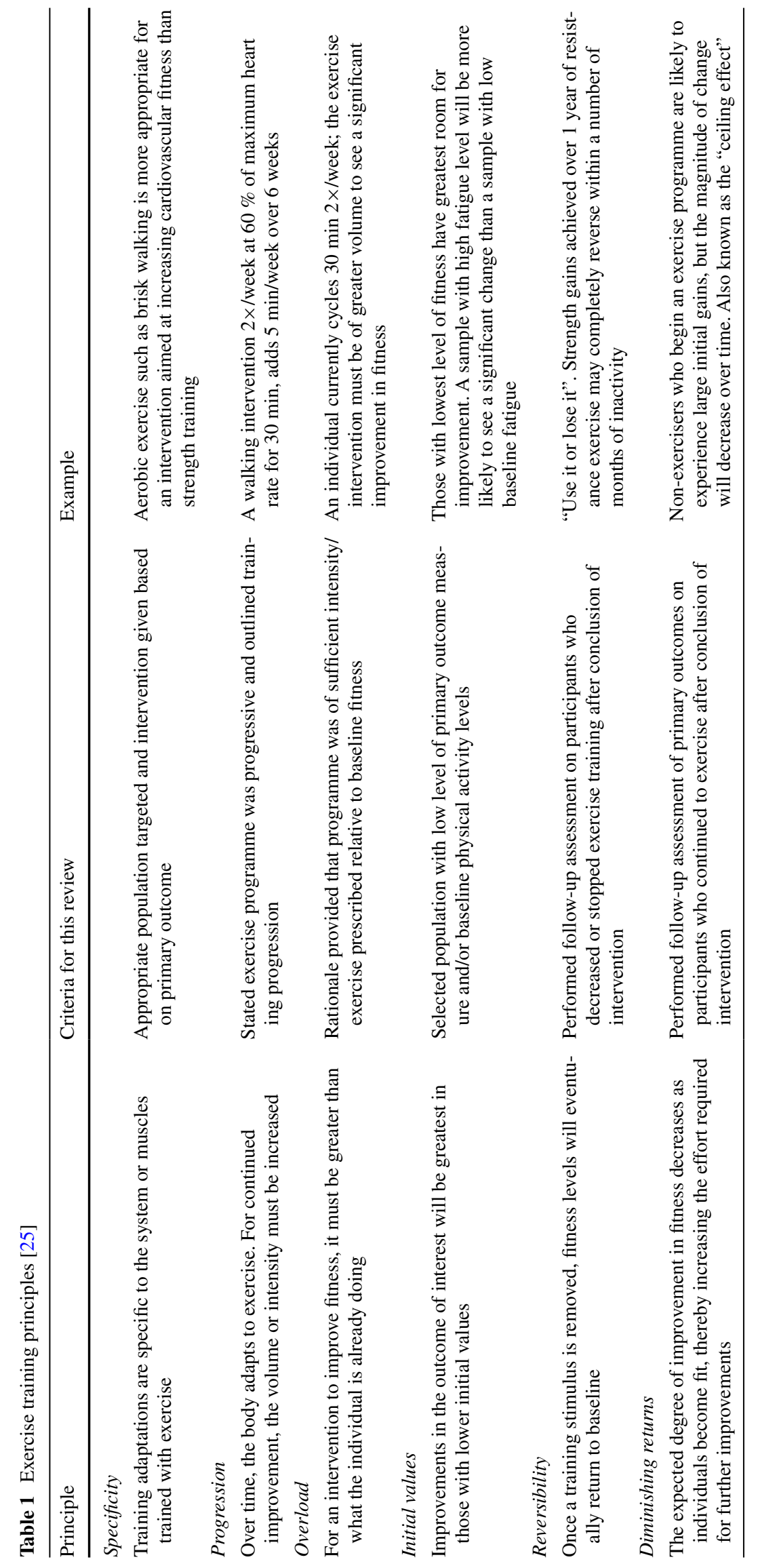


Irrespective of study design, study quality should be evaluated in a standardised manner.

This review evaluates exercise interventions in populations suffering from IM in randomised controlled, nonrandomised controlled, and uncontrolled trials investigating the effect of resistive, endurance, or balance training alone or in combination in relation to (1) the application of principles of exercise training in developing the exercise prescription, (2) the reporting of FITT components of the exercise prescriptions, (3) the adherence of participants to the prescribed intervention and to gauge (4) the methodological quality of the included studies.

\section{Methods}

\section{Search strategy}

An electronic search strategy was developed and performed by a librarian of Zurich University for the databases MEDLINE/PreMEDLINE, CINAHL, PsychINFO, EMBASE, and the Cochrane Library. The search was restricted to English, German, French, and Dutch language literature from inception of the databases up to January 2015 ("Appendix in Electronic Supplementary Material"). Combinations of medical subject headings (MeSH) and free text words related to inflammatory myopathy (inflammatory myopathy, dermatomyositits, polymyositis, inclusion body myositis, sclerodema, systemic sclerosis, systemic lupus erythematosus, Sjögren's syndrome) and exercise (e.g. exercise, endurance training, cardiovascular training, cardiopulmonary training, cardiorespiratory training, aerobic training, endurance exercise, ergometry, cycling, rowing, treadmill, resistive strength training, muscle strength training, weight-lifting strengthening programme, weightbearing strengthening programme, flexibility training, balance training, physical exercise principles, specificity, overload, progression, initial values, reversibility, diminishing returns) were used. The search results were supplemented by articles found through hand searching by scanning reference lists of identified studies.

\section{Eligibility criteria}

Studies were eligible for inclusion if they: (1) included adult ( $\geq 18$ years) patients with an idiopathic or an associated inflammatory myopathy, (2) were randomised controlled trials, non-randomised controlled trials, or uncontrolled trials, (3) evaluated the effect of resistive, endurance, or balance training alone or in combination, (4) included aerobic capacity and/or aerobic endurance, muscle strength and/or balance as a primary outcome measurement. Case series or case reports were excluded. Hands-on intervention therapies alone (i.e. mobilisation, passive movements, stretching without physical exercise), as well as relaxation training, were not considered in this review.

\section{Study selection}

After removal of duplicates, the search results were screened for eligibility by a team of two reviewers (PB/ RHK), sharing the retrieved citations. In case of disagreement between the two reviewers, a third party (BCT) served as referee. Reports of secondary analyses or on extensions from original manuscripts were not included in this review.

\section{Data extraction and synthesis}

Information on the study design, number and diagnosis of participants, type and length of intervention, and the intervention protocol were extracted from each publication. Details of the intervention protocol were abstracted using a purpose adapted data collection sheet based on systematic reviews evaluating the effects of physical exercise interventions in cancer [21] and stroke patients [22]. It included reporting of PE training principles, description of exercise training components, and participants' adherence to the training plan according to the FITT components. For each physical exercise principle, three rating categories were used, these being yes $(+)$ "reported", no (NR) "not reported", and (?) "unclearly/inconsistently reported". Corresponding to the rating of the training principles, the description of each of the four FITT components was judged with (+) if the component of the exercise prescription was reported, (NR) if the component was not reported, and (?) if it was unclearly or inconsistently reported. Participants' adherence to the exercise prescription was judged with $(+)$ if adherence to each component of the exercise prescription was reported, (NR) if adherence was not reported, and (?) if it was unclearly or inconsistently reported. Two reviewers (BCT, PB) independently collected and rated these data. In case of discrepancies, a third reviewer (RHK) was used as an adjudicator.

\section{Study quality assessment}

Methodological quality of all studies was assessed by two independent reviewers (PB and $\mathrm{BCT}$ ) using the checklist for the assessment of the methodological quality both of randomised and non-randomised studies of health-care interventions developed by Downs and Black [29]. This scale contains 27 items assessing five subscales, these being reporting (10 items), internal validity-bias (seven items), internal validity-confounding (six items), external validity (three items), and power (one item). We 
modified the scoring of the last item (study power) from a $0-5$ scale to a $0-1$ scale where 1 was scored if authors reported if and how they determined their sample size a priori [30]. Item 4 (description of the intervention) and 19 (compliance with the intervention) were scored "yes" if all FITT components were described in the method and results, respectively. According to other recommendations [31], we scored item 26 (losses to follow-up) "yes" if the drop-out rate was $<15 \%$, or if an intention-to-treat analysis was conducted. The score from this modified version ranged from 0 to 28 , with a higher score indicating higher methodological quality. For intervention studies with a one-group design, several items must be scored zero (items 5, 14, 15, 21-25), which implied a possible range score between 0 and 19 for those study designs. The arbitration of a third reviewer (RHK) was used in the event of any disagreement between the reviewers (BCT and $\mathrm{PB}$ ) for the ratings. The percentage agreement and Cohen's kappa were calculated and interpreted in accordance with Landis and Koch's benchmarks for assessing the agreement between raters, categories being poor (0), slight $(0.1-0.20)$, fair $(0.21-0.40)$, moderate $(0.41-0.60)$, substantial (0.61-0.80), and almost perfect (0.81-1.0) [32]. The PRISMA statement was followed for reporting items of this review [33, 34].

\section{Results}

\section{Study selection and characteristics}

The literature search provided a total of 1371 citations. After screening and checking for duplicates, 16 reports [20, 34-48] met all of the inclusion criteria [35-50]. Two reports were classified as a secondary analysis [43] or an extension [36] from an original study and were therefore excluded from this review (Fig. 1). Finally, 14 reports [35, 37-42, 44-50] evaluating 190 patients remained. Thirteen patients were evaluated in two studies; a 6-week randomised controlled trial [49] and a 6-month follow-up trial [50]. Relevant information was extracted (Table 2). Nine reports $[20,34,36-38,40,46-48]$ investigated patients with DM and PM [35, 37-40, 42, 48-50], four reports [39, 43-45] included patients with IBM [41, 45-47], and one report [44] evaluated PM, DM, and IBM patients. In total, $161 \mathrm{DM}$ and PM patients (121 in a chronic stage and 40 with recent disease onset) and 29 IBM patients were examined. Four reports (two PM/DM [38, 48], two IBM $[46,47])$ focused on resistance training, two on endurance training (two PM/DM $[49,50]$ ) and eight reports (five PM/ DM [35, 37, 39, 40, 42], two IBM [41, 45], and one PM/ DM and IBM [44]) on combined interventions of aerobic and resistance exercises. No study evaluated the effects of balance training. All but five studies used a one-group study design, from which were four RCTs [35, 37, 42, 49] and one [50] was a controlled trial without randomisation procedure. One RCT [42] compared a combination of PE/ oral creatine supplements against PE/placebo. Both groups performed the same exercise programme, making a comparison between the two groups concerning the effects of $\mathrm{PE}$ impossible. The length of the exercise programmes varied between 3 weeks [44] and 6 months [42, 50] (median: 12 weeks). Exercise frequencies ranged from twice daily [46] to twice per week [49-51]. Half of the studies evaluated a home exercise programme [37, 39-42, 45, 46] and the other half a supervised exercise programme in dedicated training facilities [36, 38, 44, 47-50].

\section{Application of exercise principles}

The application of exercise principles is summarised in Table 3. None of the articles reported all six training principles, five articles [20,38, 46, 47, 50] reporting four, four articles [37, 40, 42, 48] reporting two and three articles [35, $39,45]$ reporting three. The remaining two articles reported 0 [42] or 1 [39] principle. In two articles [35, 37], the training principles Reversibility and Diminishing Return were reported inconsistently. Thirteen articles [35, 37-42, 45-50] reported Specificity, 11 articles [35, 37-40, 42, 4547, 49, 50] described Initial Values, whilst seven articles described Progression [38, 39, 45-47, 49, 50] and Overload [35, 38, 45, 47-50]. Articles focusing on one training method alone (either strength [38, 46-48] or endurance training $[49,50]$ ) reported more training principles (mean $3.7 \pm 0.8)$ compared to those with a combined intervention $[35,37,39-42,44,45]$ (mean $2.1 \pm 1.2)$.

\section{Reporting of the prescription of the physical exercise training}

Reporting of the prescriptions of the training programme according to the FITT components as well as its adherence is presented in Fig. 2. Six articles [35, 38, 47-50] reported all four FITT components, five articles [37, 39-42] described three components, two articles [45, 46] reported two components, and one article [44] described 0 components. Frequency and Type were described in 13 articles [35, 37-42, 45-50], Time in 11 articles [35, 37-42, 47-50], and Intensity in seven articles [35, 38, 45, 47-50]. The quality of reporting of the intervention was better in studies focusing on only one training method compared to those including a combination of strength and endurance training (mean of $3.7 \pm 0.8$ vs. $2.6 \pm 1.2$ FITT components out of four). 


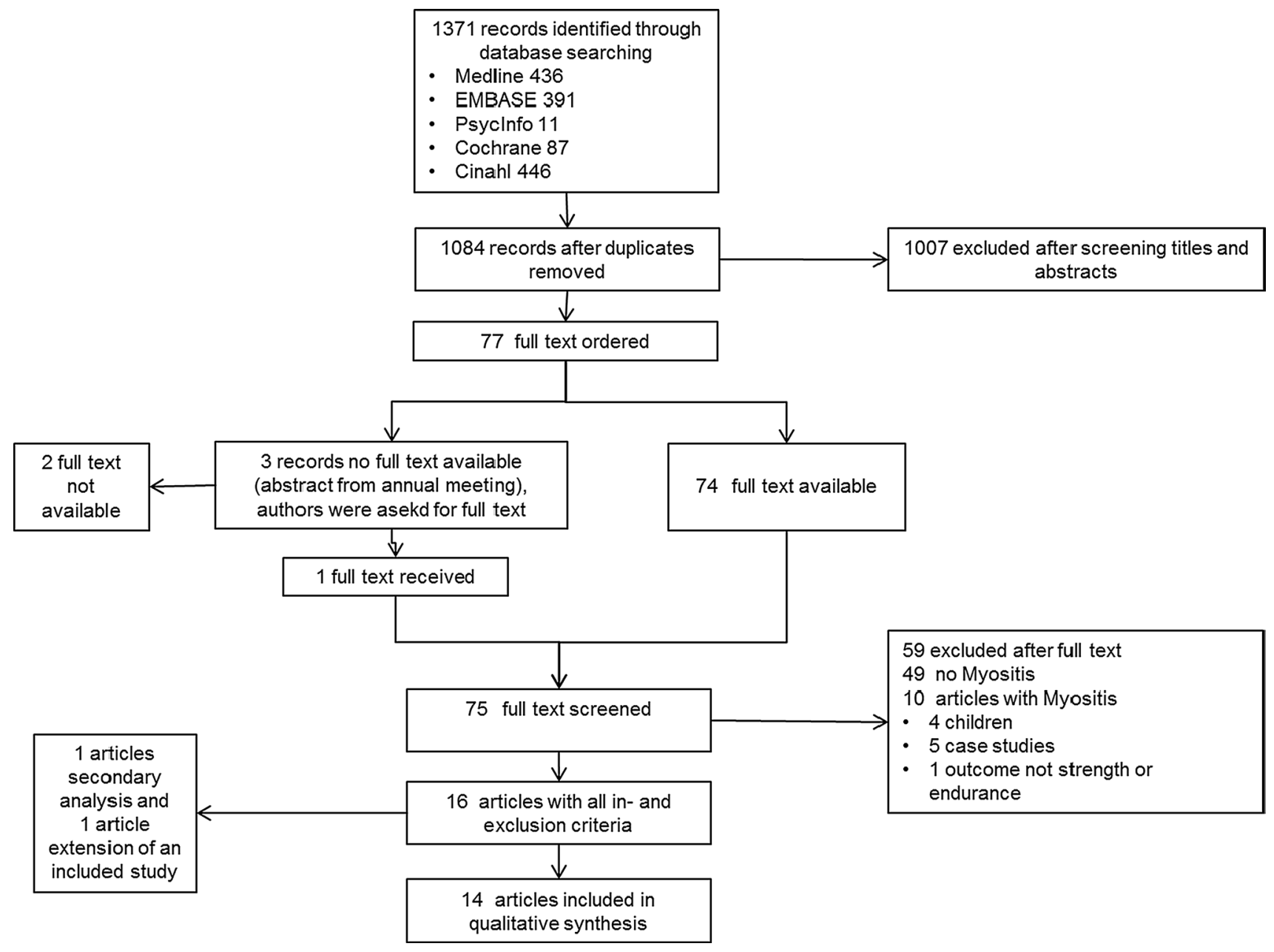

Fig. 1 Flow chart of study selection process

\section{Adherence to the exercise prescription according to the FITT components}

Four articles [37, 39, 41, 46] reported two out of four training components, one report [38] described one component, and nine reports $[35,40,42,44,45,47-50]$ did not describe the adherence of the patients to the PE programme. Frequency was reported in five [37-39, 41, 46] and Type in four reports [37, 39, 41, 46]. Intensity and Time were not mentioned in any of the included reports.

\section{Methodological quality}

The methodological quality varied widely between the reports (Fig. 3). Studies using a one-group design [38-41, 44-48] scored between 11 and 15 (mean $12.75 \pm 1.3$ ) points (maximum possible score 19). Reports with a twogroup design [35, 37, 42, 49, 50] scored between 19 and 24 (mean $21.6 \pm 1.8$; maximum possible score 28 ). The subscales internal validity-confounding had the highest quality score (86 \% yes answers), followed by the subscales internal validity-bias and reporting (each $78 \%$ yes answers), whilst external validity and power scored lowest (only $48 \%$ respectively $40 \%$ yes answers). In the subscale reporting, the item "intervention of interest" was described in six reports [35, 38, 47-50] and "actual $p$-values" were stated in five reports [35, 42, 44, 45, 50]. The items "hypothesis/aim/objective", "main outcomes to be measured", and "main findings" were described in all 14 reports. In the subscale external validity, eight reports [37-39, 42, 44, 48-50] stated if the subjects asked to participate were representative of the entire population, whilst only four reports [44, 48-50] described whether participants were representative of this population. One report [42] described the blinding of their patients regarding intervention. None of the reports provided an account of participant adherence. The total inter-rater agreement was good (kappa 0.62, SE of kappa: 0.054, 95 \% CI 0.51-0.72). The number of observed agreements between the two raters was $86.93 \%$ of the judgements. The kappa of the subscales 
Table 2 Description of studies

\begin{tabular}{|c|c|c|c|c|c|c|c|c|c|}
\hline Study & Design & $\mathrm{N}$ and diagnosis & Type of intervention & Control & Length & $\mathrm{TP}$ & FITT rep & FITT adh & D \& B \\
\hline \multicolumn{10}{|l|}{ Aerobic and resistance } \\
\hline $\begin{array}{l}\text { Alexanderson et al. } \\
\text { [40] }\end{array}$ & 1 group & $\begin{array}{c}10 \mathrm{PM} / \mathrm{DM} \\
\text { (chronic) } \\
(5 \mathrm{PM} / 5 \mathrm{DM})\end{array}$ & $\begin{array}{l}\text { Home exercise pro- } \\
\text { gramme (strength } \\
\text { and mobility exer- } \\
\text { cises and } 15 \text { min } \\
\text { walk) }\end{array}$ & - & 12 weeks & 2 & 3 & 0 & $11 / 19$ \\
\hline $\begin{array}{l}\text { Alexanderson et al. } \\
\text { [39] }\end{array}$ & 1 group & $\begin{array}{l}11 \mathrm{PM} / \mathrm{DM} \text { (acute) } \\
(7 \mathrm{PM} / 4 \mathrm{DM})\end{array}$ & $\begin{array}{l}\text { Home exercise pro- } \\
\text { gramme (strength } \\
\text { exercises and } \\
15 \text { min walk) }\end{array}$ & - & 12 weeks & 3 & 3 & 2 & $14 / 19$ \\
\hline Heikkilà et al. [44] & 1 group & $\begin{array}{l}22 \mathrm{DM} / \mathrm{PM} / \mathrm{IBM} \\
(15 \mathrm{PM} / 4 \mathrm{DM} / 3 \\
\mathrm{IBM})\end{array}$ & $\begin{array}{l}\text { Exercise-based } \\
\text { multidisciplinary } \\
\text { inpatient course }\end{array}$ & - & 3 weeks & 0 & 0 & 0 & $13 / 19$ \\
\hline Arnadottir et al. [41] & 1 group & $\begin{array}{l}7 \text { sporadic IBM } \\
\text { (chronic) }\end{array}$ & $\begin{array}{l}\text { Home exercise pro- } \\
\text { gramme (strength } \\
\text { and mobility exer- } \\
\text { cises and } 15 \text { min } \\
\text { walk) }\end{array}$ & - & 12 weeks & 1 & 3 & 2 & $12 / 19$ \\
\hline Chung et al. [42] & $\mathrm{RCT}$ & $\begin{array}{l}37 \mathrm{PM}, \mathrm{DM} \\
\text { (chronic) } \\
(22 \mathrm{PM} / 15 \mathrm{DM})\end{array}$ & $\begin{array}{l}\text { Home exercise } \\
\text { programme } \\
\text { (strength and } \\
\text { mobility exercises } \\
\text { and } 15 \text { min walk) } \\
\text { and oral creatine } \\
\text { supplements }\end{array}$ & $\begin{array}{l}\text { Home exercise } \\
\text { programme and } \\
\text { placebo }\end{array}$ & 6 months & 2 & 3 & 0 & $24 / 28$ \\
\hline Johnson et al. [45] & 1 group & $\begin{array}{l}7 \text { sporadic IBM } \\
\text { (chronic) }\end{array}$ & $\begin{array}{l}\text { Home exercise } \\
\text { programme (func- } \\
\text { tional exercise } \\
\text { programme and } \\
\text { aerobic training) }\end{array}$ & - & 12 weeks & 3 & 3 & 0 & $12 / 19$ \\
\hline Munters et al. [35] & RCT & $\begin{array}{l}21 \mathrm{PM}, \mathrm{DM} \\
\text { (chronic) } \\
(9 \mathrm{PM} / 12 \mathrm{DM})\end{array}$ & $\begin{array}{l}\text { Supervised exercise } \\
\text { programme } \\
\text { (cycling and mus- } \\
\text { cular endurance) }\end{array}$ & $\begin{array}{l}\text { Non-intervention } \\
\text { group }\end{array}$ & 12 weeks & 4 & 4 & 0 & $22 / 28$ \\
\hline $\begin{array}{l}\text { Alexanderson et al. } \\
\text { [37] }\end{array}$ & RCT & $\begin{array}{l}19 \text { PM, DM (acute) } \\
\text { (10 PM/9 DM) }\end{array}$ & $\begin{array}{l}\text { Home exercise } \\
\text { programme } \\
\text { (resistive exercise } \\
\text { programme and } \\
\text { brisk walking) }\end{array}$ & $\begin{array}{l}\text { Range of motion } \\
\text { exercise pro- } \\
\text { gramme }\end{array}$ & 24 weeks & 2 & 3 & 2 & $21 / 28$ \\
\hline \multicolumn{10}{|l|}{ Resistance only } \\
\hline Spector et al. [47] & 1 group & $\begin{array}{l}5 \text { sporadic IBM } \\
\text { (chronic) }\end{array}$ & $\begin{array}{l}\text { Supervised exercise } \\
\text { programme (pro- } \\
\text { gressive resistive } \\
\text { training) }\end{array}$ & - & 12 weeks & 4 & 4 & 0 & $12 / 19$ \\
\hline Varju et al. [48] & 1 group & $\begin{array}{l}21 \mathrm{PM}, \mathrm{DM} \\
\text { Acute: } 4 \text { PM/6 DM } \\
\text { Chronic: } 5 \text { PM/6 } \\
\text { DM }\end{array}$ & $\begin{array}{l}\text { Supervised exercise } \\
\text { programme (bend- } \\
\text { ing and stretching } \\
\text { exercise, isotonic } \\
\text { muscle training } \\
\text { and respiratory } \\
\text { training) }\end{array}$ & - & 3 weeks & 2 & 4 & 0 & $14 / 19$ \\
\hline $\begin{array}{l}\text { Alexanderson et al. } \\
\text { [38] }\end{array}$ & 1 group & $\begin{array}{l}9 \mathrm{PM}, \mathrm{DM} \text { (chronic) } \\
\text { (4 PM/5 DM) }\end{array}$ & $\begin{array}{l}\text { Supervised exercise } \\
\text { programme (inten- } \\
\text { sive muscular } \\
\text { training) }\end{array}$ & - & 7 weeks & 4 & 4 & 1 & $15 / 19$ \\
\hline
\end{tabular}


Table 2 continued

\begin{tabular}{|c|c|c|c|c|c|c|c|c|c|}
\hline Study & Design & $\mathrm{N}$ and diagnosis & Type of intervention & Control & Length & $\mathrm{TP}$ & FITT rep & FITT adh & $\mathrm{D} \& \mathrm{~B}$ \\
\hline Johnson et al. [46] & 1 group & $\begin{array}{l}7 \text { sporadic IBM } \\
\text { (chronic) }\end{array}$ & $\begin{array}{l}\text { Home exercise } \\
\text { programme (func- } \\
\text { tional exercise } \\
\text { programme) }\end{array}$ & - & 16 weeks & 4 & 2 & 2 & $12 / 19$ \\
\hline \multicolumn{10}{|l|}{ Aerobic only } \\
\hline Wiesinger et al. [49] & $\mathrm{RCT}$ & $\begin{array}{l}14 \mathrm{PM}, \mathrm{DM} \\
\text { (chronic) } \\
(4 \mathrm{PM} / 10 \mathrm{DM})\end{array}$ & $\begin{array}{l}\text { Supervised exercise } \\
\text { programme } \\
\text { (cycling and step } \\
\text { aerobic) }\end{array}$ & No training & 6 weeks & 4 & 4 & 0 & $22 / 28$ \\
\hline Wiesinger et al. [50] & $\mathrm{CT}$ & $8 \mathrm{PM}, \mathrm{DM}$ (chronic) & $\begin{array}{l}\text { Supervised exercise } \\
\text { programme } \\
\text { (cycling and step } \\
\text { aerobic) }\end{array}$ & No training & 6 months & 4 & 4 & 0 & $19 / 28$ \\
\hline
\end{tabular}

adh Reported in the result section; $C T$ controlled trial; $D M$ dermatomyositis; FITT frequency, intensity, time, and type; $D \& B$ Downs and Black checklist; $I B M$ inclusion body myositis; $P M$ polymyositis; $R C T$ randomised controlled trial; $T P$ training principles; rep reported in the "Methods" section

Table 3 Applications of the exercise training principles

\begin{tabular}{|c|c|c|c|c|c|c|}
\hline Study & $\mathrm{Sp}$ & $\operatorname{Pr}$ & Ov & IV & Rev & DR \\
\hline \multicolumn{7}{|l|}{ Aerobic and resistance } \\
\hline Alexanderson et al. [40] & + & NR & NR & + & NR & NR \\
\hline Alexanderson et al. [39] & + & + & NR & + & $\mathrm{NR}$ & NR \\
\hline Heikkilà et al. [44] & $?$ & $?$ & NR & $?$ & NR & NR \\
\hline Arnadottir et al. [41] & + & NR & NR & $?$ & NR & NR \\
\hline Chung et al. [42] & + & NR & NR & + & NR & NR \\
\hline Johnson et al. [45] & + & + & $?$ & + & NR & NR \\
\hline Munters et al. [35] & + & $?$ & + & + & $?$ & $?$ \\
\hline Alexanderson et al. [37] & + & NR & $?$ & + & $?$ & $?$ \\
\hline \multicolumn{7}{|l|}{ Resistance only } \\
\hline Spector et al. [47] & + & + & + & + & NR & NR \\
\hline Varju et al. [48] & + & $?$ & + & $?$ & NR & NR \\
\hline Alexanderson et al. [38] & + & + & + & + & NR & NR \\
\hline Johnson et al. [46] & + & + & + & + & NR & NR \\
\hline \multicolumn{7}{|l|}{ Aerobic only } \\
\hline Wiesinger et al. [49] & + & + & + & + & NR & NR \\
\hline Wiesinger et al. [50] & + & + & + & + & NR & NR \\
\hline
\end{tabular}

+: reported, NR: not reported, ?: unclearly or inconsistently reported varied between poor (kappa 0.05 , external validity) to very good (kappa 0.80, confounding).

\section{Discussion}

The results of this review demonstrated that application of training principles and methodological quality were both reported inconsistently in those papers studied, whilst FITT components were reported more consistently in training prescriptions than in result sections. Eighty per cent of studies applied at least three out of four FITT components in their exercise prescriptions. However, none of the studies provided complete accounts of the level of adherence to the PE protocol. Sixty-four per cent of the studies provided no details on adherence to their training protocol.

Regarding IM patients, there were only three RCTs comparing a PE intervention with a non-exercising control group. The majority of the published studies were performed as a one-group design. Furthermore, the sample sizes of the included studies were low and varied between five and 37 patients, whereas half of the studies included 10 or less participants. In addition, the involved studies investigated different subcategories of IM (chronic or recent 

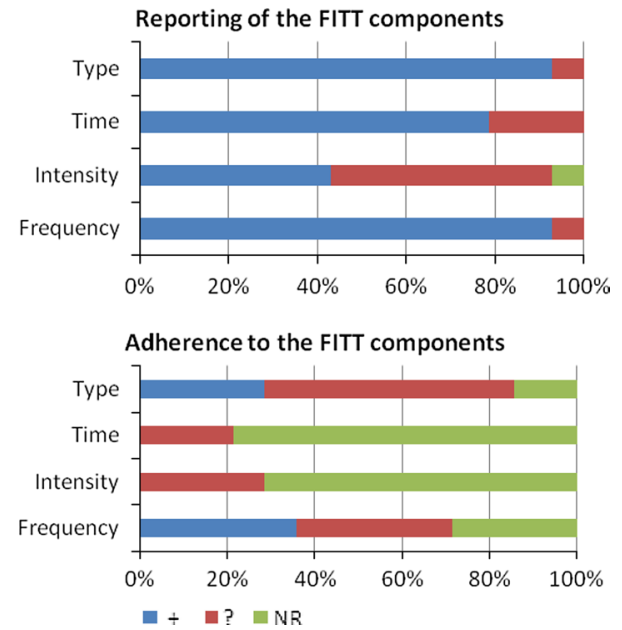

Fig. 2 Reporting of the planned exercise prescription components. $(+)$ The percentage of studies that reported the component of exercise prescription. (?) The percentage of studies that was unclear or inconsistently with their reporting of the exercise prescription. (NR) The percentage of studies that did not report the component of the exercise prescription

onset) and different types of intervention. Taken together, the evidence for PE in IM is still weak and it is not yet known which training prescription is the most effective. Therefore, no final conclusion regarding the evidence for
PE in IM patients can be drawn. These facts are indicative of the still sparsely investigated topic of exercise interventions for patients with inflammatory disease $[18,19]$.

\section{Application of the principles of exercise training}

Specificity was the most commonly applied training principle. Ninety-three per cent of the reviewed trials matched the training mode with their primary outcome measure. This result is in agreement with previous studies about the application of principles of PE training in cancer [20,21] and stroke [22] survivors. Although lower values ( 89 and $64 \%$, respectively) were reported in cancer and stroke survivors, specificity was the most applied exercise training principle. In our review, only one study [44], assessing an exercise-based multidisciplinary inpatient course, did not report specificity. In this study, PE was a single part of a comprehensive rehabilitation programme and each participant performed different components of exercise. In contrast, progression and overload were reported in only $50 \%$ of the included studies. Other authors found comparable values for the principle progression $(41,26$, and $76 \%$, respectively) and lower values for the principle overload (31, 37 , and $49 \%$, respectively) [20-22]. The principle of overload states that, to improve fitness, the intervention must be greater than what the individual is already doing (Table 1). Therefore, without knowing the baseline fitness levels of
Fig. 3 Methodological quality assessed with the Downs and Black checklist. *Maximal possible point score: 28 . **Maximal possible point score: 19

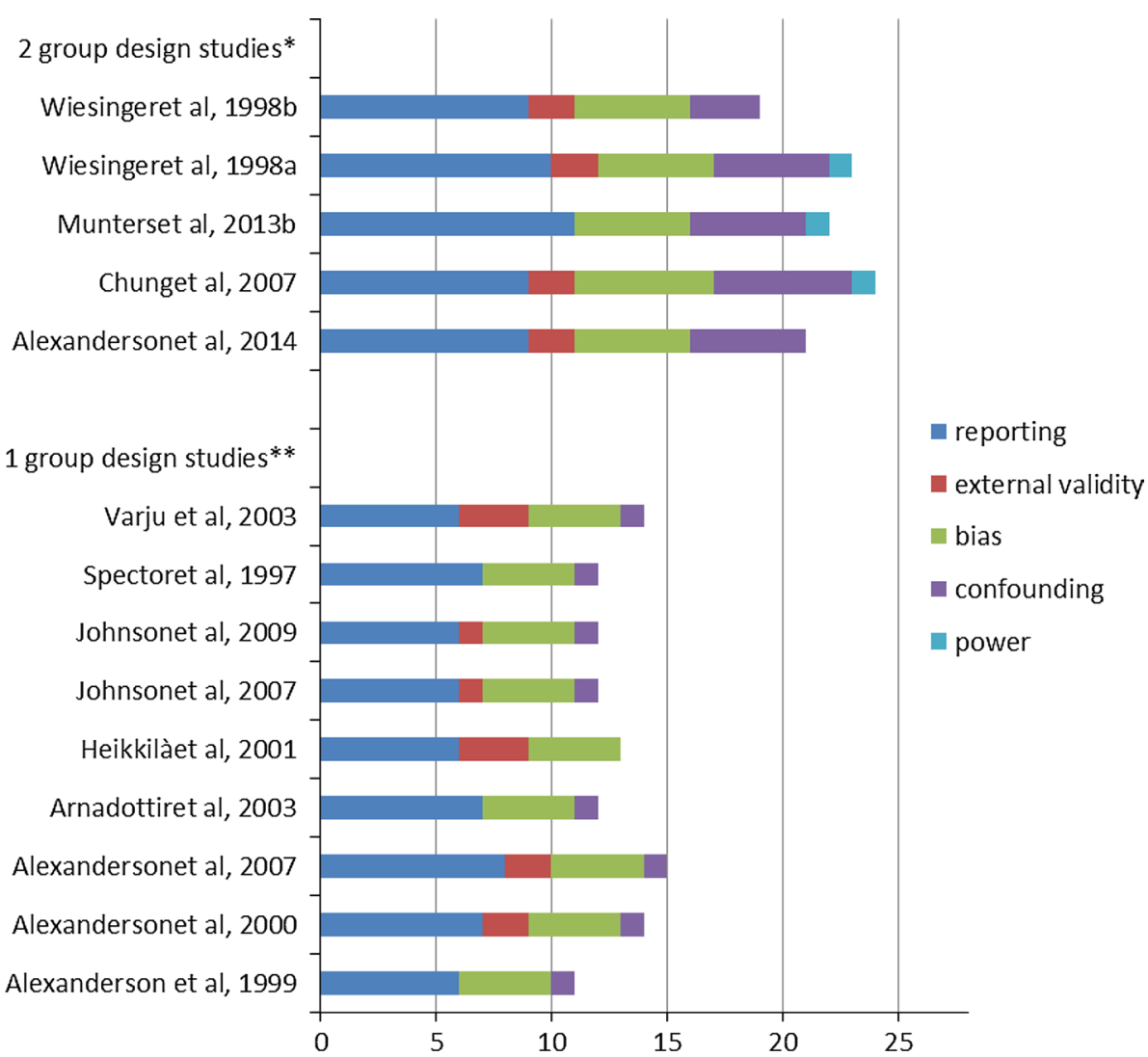


studied individuals, it is impossible to determine whether adequate training intensities and volumes have been used. In studies evaluating resistance training, a valid and feasible way to assess baseline value is to perform a 1,5 , or 10 voluntary repetition maximum test for the target muscle groups [35, 38, 47] or to count the maximum number of times that participants were able to repeat the exercise in the initial assessment session [46, 48]. In studies investigating aerobic exercise, $\mathrm{Vo}_{2}$ max [35] or maximum heart rate $[49,50]$ could be used to assess initial value. If the training matches the baseline level of the individual, improvement will occur. Thus, to assure continued improvement, the training intensity and/or volume must be adjusted after a certain period of training. Progression can be conducted in different ways. In order to maintain the same absolute training stimulus, the intensity or volume of an exercise must be increased continuously. Muscular strength training in IM patients can be modulated by increasing the level of resistance or the number of exercises, repetitions or sets [38, 45-47]. In cycle training, the resistance can be increased [49, 50]. The principle of initial value was considered in $79 \%$ of the included studies. This rate is higher compared to studies including cancer [20-22] and stroke patients [26]. One reason for this difference could be that our reviewed studies included patients with muscular diseases. These patients have by definition impaired muscle function [9] and therefore a low initial value in muscle strength. This allows greatest room for improvement. Reversibility and diminishing return can only be judged in studies that investigate a follow-up after conclusion of the initial intervention. The two studies $[35,37]$ which performed a follow-up after the end of the intervention did not report whether the patients continued, stopped, or decreased with the PE programme. For that reason, both principles could not be judged unambiguously.

An explicit conclusion concerning efficacy of a specific exercise programme can only be drawn if at least the first four principles (specificity, progression, overload, initial value) are clearly stated. Otherwise it is not possible to distinguish if exercise training per se is not indicated or if the prescribed exercise programme was inadequate or under dosed. Lack of attention to these principles may affect the study impact and effect of exercise training may thus be underestimated. To investigate long-term effect, the two principles of reversibility and diminishing return need to be included in PE studies. Knowing that exercise has no depot effect [25], it would be important to study how patients can be motivated to continue exercise training after study conclusion.

\section{Reporting of the prescription of the physical exercise training and adherence}

Whilst only one paper [44] failed to report frequency and type of exercise prescribed, eight out of 14 reports did not adequately report the complete FITT components. Although intensity is a key component, it was the least reported one. If intensity is under a certain threshold, patients will probably not benefit from their training effort. Conversely, if the PE intensity is too high, patients' safety could be impaired. Due to the lack of equipment, it is not always feasible to measure intensity in absolute values, e.g. maximal oxygen consumption or measurement units such as watt, newton, or maximum peak torque. Nevertheless, intensity can always be described in a relative way. For resistance training, a 1,5 , or 10 repetition maximum can be tested. Then percentages of these results can be taken for the desired training intensity. For aerobic exercise, the percentage of the theoretical maximum heart rate could be used. Furthermore, a subjective way to measure intensity is the Borg's Rating of Perceived Exertion and Pain (RPE) Scales [52]. This scale values range from 6 to 20, where 6 is a very, very light and 20 a very, very hard exertion. This scale is an affordable, practical, and valid tool to monitor and prescribe exercise intensity. Exercise at an RPE of 11-13 (low) may be recommended for less trained individuals, whilst a RPE of 13-15 may be recommended where training should be more intense whilst still retaining an aerobic training effect [53].

Whilst reporting the PE training prescription is important, it is also necessary to identify which patients actually undertook PE and persisted with it. Only if adherence to the FITT components is completely covered and reported will the actual performed PE training be evident and thus conclusions for further research or practice be more safely drawn. To start and maintain an exercise programme is a huge challenge, particularly for inactive persons [54]. Therefore, it is important to know which PE training programme participants actually perform and how often they have performed it. If participants do not exercise regularly, the training goal may not be achieved. Additionally, it is important to know if participants had to modify their programme, for example because they were unable to perform the original planned intensity or training period. Therefore, besides information on frequency and type of exercise, additional information about intensity and time needed to perform the exercises is fundamental. Unfortunately, none of our included studies reported this information in sufficient detail. The poor reporting of adherence seems to be a common weakness in PE studies. This was also highlighted in studies with other diseases [20-22]. It is a challenge to control and verify adherence, especially in home-based training programmes. Patients could be motivated to fill out training logs and to send them back regularly. As known from questionnaires relating to physical activity, people tend to give socially desirable answers [55]. This risk also exists in diaries, as people may overestimate the level of performed exercises. One possibility for overcoming this 
shortcoming could be an e-health home-based training programme, using telecommunication technologies [56]. Such a programme would allow patients to report their performed exercise volume, intensity and perceived exertion immediately. Based on this information they receive direct feedback and their training programme could be adapted regularly. The training volume and intensity would be transparent and rehabilitation specialists would be able to react immediately if some patients did not adhere to the PE programme. In a recently published study investigating independent living, older adults showed that adoption of assistive technology devices for physical intervention tends to motivate and retain exercising for longer periods of time [57].

\section{Methodological quality}

One of the most prevalent methodological shortcomings was the insufficient power of the studies, only two of which reported how sample size was determined a priori. In the subscale internal validity-confounding, the items concerning the different intervention groups (four out of five items) could not be scored for those studies which had a one-group design. Because controlling for extraneous variables is not possible in studies with only one group, these are susceptible to confounding and tend to exaggerate the beneficial effects of interventions [58].

The item "lost to follow-up" was scored positive in $86 \%$ of all studies. Compared with other exercise studies, attrition bias is not so prevalent in our review. This may be because the intervention durations of our studies were rather short and study samples small. This makes it easier to support and motivate individual participants. A common problem in the subscale internal validity-bias in studies with exercise interventions is the blinding of the participants and the reliability of compliance reporting. It is almost impossible to blind participants regarding an exercise intervention [59]. Only one RCT was able to blind its participants, and this was because it compared exercise training in combination with oral creating supplements with exercise training in combination with placebo. The subscale external validity is scored between 4 and 8 points. Although external validity is important for ascertaining implications for clinical practice, most checklists in fact ignore this aspect. To date, the best way to assess external validity is still unknown [29]. In the subscale reporting, the "description of the intervention" and "actual probability value" are the weakest scored items. The methodological quality of future studies may be improved if authors provide all of the information requested by the Risk of Bias checklist for RCTs [60] or the Downs and Black checklist [29] for non-randomised studies.

\section{Strength and limitations}

Although the intervention is the essence of each experimental study, its detailed description is often neglected in those trials evaluating the effect of PE training. Poor reporting of the intervention may bias the study outcomes in a way which is comparable to poor reporting of the methodological quality [24]. The strength of our study is that we evaluated the quality of the reporting and performing of the intervention as well as the methodological quality. Furthermore, we used a comprehensive search strategy in standard bibliographic databases to identify potential studies. Nevertheless, some limitations remain. Firstly, as we had to include studies with different study designs, nine out of 14 studies had no control group. Therefore, the risk of selection bias and confounding is greater than in a review of RCTs [58]. To address these limitations, we used a comprehensive quality checklist which deals with randomised and non-randomised studies. Secondly, we included different subtypes and phases of myositis. Thus, the included participants were very heterogeneous and training modalities could not be compared between the included studies. As a result, it was not possible to perform a meta-analysis. Thirdly, we could only judge the information authors described in their published articles. Hence, it is possible that some studies considered the principles of PE but did not report it. Such studies would thus be underrated in our review.

Fourthly, we did not focus on the outcome measures of the included studies. All studies reported aerobic capacity, aerobic endurance, or muscle strength as a primary outcome measurement. As reported in a previous review, both aerobic and strength training seems to have a beneficial effect on strength and endurance [23]. Additionally, all included studies evaluated laboratory measurement such as erythrocyte sedimentation rate, C-reactive protein or creatinine phosphokinase and/or inflammatory cell infiltrates. None of the reports found an aggravation of these muscle enzymes or of the inflammatory cell infiltrates.

Finally, we were unable to determine whether applying the exercise training principles explicitly influenced outcomes. Our studies were heterogeneous concerning design, sample size, and methodological quality. This means that too many factors had the potential to influence the outcome of the study. Thus, no conclusion could be drawn regarding the impact of the application of principles of exercise training on outcome.

\section{Call for transparency to facilitate evidence-based practice}

The steadily growing health market calls for effectively and efficiently performed PE interventions. Therefore, it is 
important that the goals for PE training are reasonable and attainable [25]. Whilst fitness levels of patients vary widely, these aims are best achieved with a custom-made and individually tailored training programme, with parameters that can be adjusted from workout to workout. These parameters include type, volume, intensity, and order of physical exercise as well as the frequency and length of training and the length of rest periods [25]. To achieve the desired training effect, PE programmes should consider the training principles [25] and the training parameters should be reported, e.g. by use of FITT components [26]. Only with a complete description of the PE strategy can clinicians reliably implement interventions that are effective. Furthermore, investigators can replicate or further develop research findings. To improve the completeness of reporting, and ultimately improve replicability of exercise interventions with IM patients, the Template for Intervention Description and Replication (TIDieR) checklist and guide might proof useful [24]. Using this checklist in conjunction with the CONSORT checklist [27] makes it easier for authors to structure description of their interventions, for reviewers and editors to assess the descriptions, and for clinicians to replicate the interventions. Thus, future methodological well-designed RCTs, including a detailed prescription of the physical exercise intervention, should be designed and evaluated in patients with IM.

\section{Conclusion}

This review showed that exercise training principles and FITT components in intervention studies for myositis patients were not systematically reported. When failing to apply the training principles, exercise interventions may be of insufficient intensity or may be executed under suboptimal circumstances. As a result, the effect of the physical exercise intervention may be underestimated and time allotted for therapy is not used effectively and efficiently. Furthermore, if the FITT components of physical exercise training and the adherence to these components are not explicitly reported, the intervention is not reproducible and it is difficult to transfer the results to the clinical setting. Therefore, future studies should consider the Template for Intervention Description and Replication checklist and guide in order to describe the training principles and report FITT prescriptions and, thus, allow development of replicable exercise recommendations for IM patients.

Acknowledgments The authors thank Martina Gosteli for performing the search strategy. Further thanks goes to Dr. Martin Watson for proof reading the manuscript on English and structure.

\section{Compliance with ethical standards}

Conflict of interest The authors declare that they have no conflict of interest.

\section{References}

1. Greenberg SA (2008) Inflammatory myopathies: evaluation and management. Semin Neurol 28(2):241-249. doi:10.105 5/s-2008-1062267

2. Vincze M, Danko K (2012) Idiopathic inflammatory myopathies. Best Pract Res Clin Rheumatol 26(1):25-45. doi:10.1016/j. berh.2012.1001.1013

3. Mastaglia FL, Phillips BA (2002) Idiopathic inflammatory myopathies: epidemiology, classification, and diagnostic criteria. Rheum Dis Clin North Am 28(4):723-741

4. Furst DE, Amato AA, Iorga SR, Gajria K, Fernandes AW (2012) Epidemiology of adult idiopathic inflammatory myopathies in a U.S. managed care plan. Muscle Nerve 45(5):676-683. doi:10.1002/mus.23302

5. Smoyer-Tomic KE, Amato AA, Fernandes AW (2012) Incidence and prevalence of idiopathic inflammatory myopathies among commercially insured, Medicare supplemental insured, and Medicaid enrolled populations: an administrative claims analysis. BMC Musculoskel Disord 13:103. doi:10.1186/1471-2474-1113-1103

6. Bernatsky S, Panopalis P, Pineau CA, Hudson M, St Pierre Y, Clarke AE (2011) Healthcare costs of inflammatory myopathies. J Rheumatol 38(5):885-888. doi:10.3899/jrheum.101083 (Epub 102011 Mar 101081)

7. Furst DE, Amato AA, Iorga SR, Bancroft T, Fernandes AW (2012) Medical costs and health-care resource use in patients with inflammatory myopathies in an insured population. Muscle Nerve 46(4):496-505. doi:10.1002/mus.23384

8. Dalakas MC (1991) Polymyositis, dermatomyositis and inclusion-body myositis. N Engl J Med 325(21):1487-1498. doi:10.1056/nejm199111213252107

9. Bohan A, Peter JB (1975) Polymyositis and dermatomyositis (second of two parts). N Engl J Med 292(8):403-407. doi:10.1056/nejm197502202920807

10. Horlings CG, van Engelen BG, Allum JH, Bloem BR (2008) A weak balance: the contribution of muscle weakness to postural instability and falls. Nat Clin Pract Neurol 4(9):504-515. doi:10.1038/ncpneuro0886

11. Szulc P, Beck TJ, Marchand F, Delmas PD (2005) Low skeletal muscle mass is associated with poor structural parameters of bone and impaired balance in elderly men-the MINOS study. J Bone Miner Res 20(5):721-729 (Epub 2004 Dec 2020)

12. Alexanderson H, Lundberg IE (2012) Exercise as a therapeutic modality in patients with idiopathic inflammatory myopathies. Curr Opin Rheumatol 24(2):201-207. doi:10.1097/ BOR.0b013e32834f19f5

13. Lundberg IE, Vencovsky J, Alexanderson H (2014) Therapy of myositis: biological and physical. Curr Opin Rheumatol 26(6):704-711

14. Woods JA, Vieira VJ, Keylock KT (2006) Exercise, inflammation, and innate immunity. Neurol Clin 24(3):585-599. doi:10.1016/j.ncl.2006.03.008

15. Gielen S, Adams V, Mobius-Winkler S, Linke A, Erbs S, Yu J, Kempf W, Schubert A, Schuler G, Hambrecht R (2003) Antiinflammatory effects of exercise training in the skeletal muscle of patients with chronic heart failure. J Am Coll Cardiol 42(5):861-868

16. Boström C, Dupré B, Tengvar P, Jansson E, Opava CH, Lundberg IE (2008) Aerobic capacity correlates to self-assessed physical function but not to overall disease activity or organ damage 
in women with systemic lupus erythematosus with low-to-moderate disease activity and organ damage. Lupus 17(2):100-104. doi:10.1177/0961203307085670

17. Mathur N, Pedersen BK (2008) Exercise as a mean to control low-grade systemic inflammation. Mediat Inflamm 2008:109502. doi:10.1155/2008/109502

18. Nader GA, Lundberg IE (2009) Exercise as an anti-inflammatory intervention to combat inflammatory diseases of muscle. Curr Opin Rheumatol 21(6):599-603. doi:10.1097/ BOR.0b013e3283319d53

19. Perandini LA, de Sa-Pinto AL, Roschel H, Benatti FB, Lima FR, Bonfa E, Gualano B (2012) Exercise as a therapeutic tool to counteract inflammation and clinical symptoms in autoimmune rheumatic diseases. Autoimmun Rev 12(2):218-224. doi:10.1016/j.autrev.2012.06.007

20. Winters-Stone KM, Neil SE, Campbell KL (2013) Attention to principles of exercise training: a review of exercise studies for survivors of cancers other than breast. Br J Sports Med. doi:10.1136/bjsports-2012-091732

21. Campbell KL, Neil SE, Winters-Stone KM (2012) Review of exercise studies in breast cancer survivors: attention to principles of exercise training. Br J Sports Med 46(13):909-916. doi:10.1136/bjsports-2010-082719

22. Ammann BC, Knols RH, Baschung P, de Bie RA, de Bruin ED (2014) Application of principles of exercise training in sub-acute and chronic stroke survivors: a systematic review. BMC Neurol 14(1):167. doi:10.1186/s12883-014-0167-2

23. Habers GE, Takken T (2011) Safety and efficacy of exercise training in patients with an idiopathic inflammatory myopathy: a systematic review (provisional abstract). Rheumatology 50(11):2113-2124

24. Hoffmann TC, Glasziou PP, Boutron I, Milne R, Perera R, Moher D et al (2014) Better reporting of interventions: template for intervention description and replication (TIDieR) checklist and guide. BMJ 348:g1687

25. Hoffmann J (2002) Physiological aspects of sport training and performance. Human Kinetics, Champaign

26. Reimer DJ (1998) Physical fitness training. In: Field manual no 21-20: 241. US-Army, Washington, DC

27. Schulz KF, Altman DG, Moher D (2010) CONSORT 2010 statement: updated guidelines for reporting parallel group randomised trials. J Clin Epidemiol 63(8):834-840

28. Deeks JJ, Dinnes J, D'Amico R, Sowden AJ, Sakarovitch C, Song F, Petticrew M, Altman DG (2003) Evaluating non-randomised intervention studies. Health Technol Assess 7(27):iii-x, 1-173

29. Downs SH, Black N (1998) The feasibility of creating a checklist for the assessment of the methodological quality both of randomised and non-randomised studies of health care interventions. J Epidemiol Community Health 52(6):377-384

30. Schoene D, Valenzuela T, Lord SR, de Bruin ED (2014) The effect of interactive cognitive-motor training in reducing fall risk in older people: a systematic review. BMC Geriatr 14:107. doi:10.1186/1471-2318-14-107

31. Hegenscheidt S, Harth A, Scherfer E (2010) PEDro-Skala. http:// www.pedro.org.au/german/downloads/pedro-scale/. Accessed 7 Aug 2015

32. Landis JR, Koch GG (1977) The measurement of observer agreement for categorical data. Biometrics 33(1):159-174

33. Liberati A, Altman DG, Tetzlaff J, Mulrow C, Gotzsche PC, Ioannidis JP, Clarke M, Devereaux PJ, Kleijnen J, Moher D (2009) The PRISMA statement for reporting systematic reviews and meta-analyses of studies that evaluate health care interventions: explanation and elaboration. PLoS Med 6(7):e1000100. doi:10.1371/journal.pmed.1000100

34. Moher D, Liberati A, Tetzlaff J, Altman DG (2009) Preferred reporting items for systematic reviews and meta-analyses: the PRISMA statement. J Clin Epidemiol 62(10):1006-1012. doi:10.1016/j.jclinepi.2009.06.005

35. Alemo Munters L, Dastmalchi M, Andgren V, Emilson C, Bergegård J, Regardt $\mathrm{M}$, Johansson $\mathrm{A}$, Orefelt Tholander I, Hanna B, Lidén M, Esbjörnsson M, Alexanderson H (2013) Improvement in health and possible reduction in disease activity using endurance exercise in patients with established polymyositis and dermatomyositis: a multicenter randomized controlled trial with a 1-year open extension followup. Arthritis Care Res 65(12):1959-1968. doi:10.1002/acr.22068

36. Alemo Munters L, Dastmalchi M, Katz A, Esbjörnsson M, Loell I, Hanna B, Lidén M, Westerblad H, Lundberg IE, Alexanderson H (2013) Improved exercise performance and increased aerobic capacity after endurance training of patients with stable polymyositis and dermatomyositis. Arthritis Res Ther 15(4):R83

37. Alexanderson H, Alemo Munters L, Dastmalchi M, Loell I, Heimburger M, Opava CH, Lundberg IE (2014) Resistive home exercise in patients with recent-onset polymyositis and dermatomyositis-a randomized controlled single-blinded study with a 2-year followup. J Rheumatol. doi:10.3899/ jrheum. 131145

38. Alexanderson $\mathrm{H}$, Dastmalchi $\mathrm{M}$, Esbjornsson-Liljedahl $\mathrm{M}$, Opava CH, Lundberg IE (2007) Benefits of intensive resistance training in patients with chronic polymyositis or dermatomyositis. Arthritis Rheum 57(5):768-777. doi:10.1002/art.22780

39. Alexanderson H, Stenstrom CH, Jenner G, Lundberg I (2000) The safety of a resistive home exercise program in patients with recent onset active polymyositis or dermatomyositis. Scand J Rheumatol 29(5):295-301

40. Alexanderson H, Stenstrom CH, Lundberg I (1999) Safety of a home exercise programme in patients with polymyositis and dermatomyositis: a pilot study. Rheumatology (Oxford) 38(7):608-611

41. Arnardottir S, Alexanderson H, Lundberg IE, Borg K (2003) Sporadic inclusion body myositis: pilot study on the effects of a home exercise program on muscle function, histopathology and inflammatory reaction. J Rehabil Med 35(1):31-35

42. Chung YL, Alexanderson H, Pipitone N, Morrison C, Dastmalchi M, Stahl-Hallengren C, Richards S, Thomas EL, Hamilton G, Bell JD, Lundberg IE, Scott DL (2007) Creatine supplements in patients with idiopathic inflammatory myopathies who are clinically weak after conventional pharmacologic treatment: six-month, double-blind, randomized, placebo-controlled trial. Arthritis Rheum 57(4):694-702. doi:10.1002/art.22687

43. Dastmalchi M, Alexanderson H, Loell I, Stahlberg M, Borg K, Lundberg IE, Esbjornsson M (2007) Effect of physical training on the proportion of slow-twitch type I muscle fibers, a novel nonimmune-mediated mechanism for muscle impairment in polymyositis or dermatomyositis. Arthritis Rheum 57(7):13031310. doi:10.1002/art.22996

44. Heikkilä S, Viitanen JV, Kautiainen H, Rajamäki T, Mäntyvuo P, Harju T (2001) Rehabilitation in myositis: preliminary study. Physiotherapy 87(6):301-309

45. Johnson LG, Collier KE, Edwards DJ, Philippe DL, Eastwood PR, Walters SE, Thickbroom GW, Mastaglia FL (2009) Improvement in aerobic capacity after an exercise program in sporadic inclusion body myositis. J Clin Neuromuscul Dis 10(4):178184. doi:10.1097/CND.0b013e3181a23c86

46. Johnson LG, Edwards DJ, Walters S, Thickbroom GW, Mastaglia FL (2007) The effectiveness of an individualized, home-based functional exercise program for patients with sporadic inclusion body myositis. J Clin Neuromuscul Dis 8(4):187-194

47. Spector SA, Lemmer JT, Koffman BM, Fleisher TA, Feuerstein IM, Hurley BF, Dalakas MC (1997) Safety and efficacy of strength training in patients with sporadic inclusion body myositis. Muscle Nerve 20(10):1242-1248 
48. Varju C, Petho E, Kutas R, Czirjak L (2003) The effect of physical exercise following acute disease exacerbation in patients with dermato/polymyositis. Clin Rehabil 17(1):83-87

49. Wiesinger GF, Quittan M, Aringer M, Seeber A, Volc-Platzer B, Smolen J, Graninger W (1998) Improvement of physical fitness and muscle strength in polymyositis/dermatomyositis patients by a training programme. Br J Rheumatol 37(2):196-200

50. Wiesinger GF, Quittan M, Graninger M, Seeber A, Ebenbichler G, Sturm B, Kerschan K, Smolen J, Graninger W (1998) Benefit of 6 months long-term physical training in polymyositis/dermatomyositis patients. Br J Rheumatol 37(12):1338-1342

51. Alexanderson H, Bergegård J, Björnådal L, Nordin A (2014) Intensive aerobic and muscle endurance exercise in patients with systemic sclerosis: a pilot study. BMC Res Notes 7(1):86

52. Borg G (1998) Borg's rating of perceived exertion and pain scales. Human Kinetics, Champaign

53. Scherr J, Wolfarth B, Christle JW, Pressler A, Wagenpfeil S, Halle M (2013) Associations between Borg's rating of perceived exertion and physiological measures of exercise intensity, pp 1439-6327 (electronic)

54. Allender S, Cowburn G, Foster C (2006) Understanding participation in sport and physical activity among children and adults: a review of qualitative studies, pp 0268-1153 (print)
55. van de Mortel TF (2008) Faking It: social desirability response bias in self-report research. Aust J Adv Nurs 25(4):40-48

56. Russell TG (2007) Physical rehabilitation using telemedicine. J Telemed Telecare 13(5):217-220. doi: $10.1258 / 135763307781458886$

57. Silveira P, van de Langenberg R, van Het Reve E, Daniel F, Casati F, de Bruin ED (2013) Tablet-based strength-balance training to motivate and improve adherence to exercise in independently living older people: a phase II preclinical exploratory trial. J Med Internet Res 15(8):e159. doi:10.2196/jmir.2579

58. Higgins J, Green S (2011) Cochrane handbook for systematic reviews of interventions version 5.1.0. Accessed 10 Jan 2014

59. Hulley SB, Cummings S, Browner WS, Grady DG, Newman TB (2007) Designing clinical research. Lippincott Williams and Wlkins, Philadelphia

60. Higgins JP, Altman DG, Gotzsche PC, Juni P, Moher D, Oxman AD, Savovic J, Schulz KF, Weeks L, Sterne JA (2011) The Cochrane Collaboration's tool for assessing risk of bias in randomised trials. BMJ 343:d5928 